Article

\title{
Cost Optimization of Wastewater and Septage Treatment Process
}

\author{
Beata Karolinczak ${ }^{1, *(D)}$, Rafał Miłaszewski ${ }^{2}$ and Wojciech Dąbrowski ${ }^{3}$ (D) \\ 1 Faculty of Building Services, Hydro and Environmental Engineering, Warsaw University of Technology, \\ 20 Nowowiejska St., 00-653 Warsaw, Poland \\ 2 Faculty of Biology and Environmental Sciences, Cardinal Wyszyński University in Warsaw, 1/3 Wóycickiego \\ St., 01-938 Warsaw, Poland; r.milaszewski@uksw.edu.pl \\ 3 Faculty of Civil Engineering and Environmental Science, Bialystok University of Technology, 45E Wiejska St., \\ 15-351 Bialystok, Poland; w.dabrowski@pb.edu.pl \\ * Correspondence: beata.karolinczak@pw.edu.pl
}

Received: 19 October 2020; Accepted: 29 November 2020; Published: 3 December 2020

\begin{abstract}
Analysis of the current knowledge has revealed the lack of a method for increasing the cost-effectiveness of wastewater and septage treatment in plants overloaded by contamination. This was the premise for undertaking research on the process of septage pre-treatment in a subsurface vertical flow constructed wetland (SS-VF) prior to its input into the biological section of a municipal treatment plant. In previous research the authors have indicated that this allows for a significant reduction in the value of pollution indicators. The objective of this paper is to assess the cost-effectiveness of this process by means of an optimization model. The decision variable was the coefficient of septage stream distribution into the quantity directed to the SS-VF bed in relation to its total quantity. The optimization criterion was the minimization of the expected annual cost of wastewater and septage treatment. Verification of the model has shown that it is reasonable to subject all septage to the pre-treatment in a SS-VF bed for small wastewater treatment plant (WWTPs) located in rural areas. The bigger the septage pollution load is, the greater the reduction in the treatment costs. The proposed solution is less cost-effective in urban areas, where the construction of a SS-VF bed requires land purchase and additional costs of its adjustment. Optimization results largely depend on the cost function, so it is important to build it on reliable local data.
\end{abstract}

Keywords: cost optimization; wastewater treatment; septage treatment; vertical flow constructed wetland

\section{Introduction}

Finding cost-effective methods of wastewater treatment is an important, but rarely studied issue in literature [1-3]. Small wastewater treatment plants (WWTPs) are a challenge to wastewater engineers $[4,5]$. Not only technical but economic and social aspects should also be taken into account when designing them. This creates the need to optimize costs of wastewater and septage treatment.

Septage is wastewater temporarily collected in cesspools and periodically delivered to municipal WWTPs. Septage is treated alongside the wastewater stream, although it is characterized by a much higher concentration of pollutants than municipal wastewater.

The literature describes the problem of the negative impact of an excessive pollutant load in septage on the process of biological wastewater treatment [6,7]. The most serious problems occur in small, hydraulically unloaded WWTPs [8,9]. The real pollutant load significantly differs from the design assumptions, which causes serious disturbances in the operation of activated sludge and trickling filters [10]. This, in turn, threatens the quality of treated wastewater and, in extreme cases, 
failure of the entire system. So far, the problem has not been solved by equipping the WWTP with receiving stations and retention tanks. While searching for a solution to this problem, the application of a subsurface vertical flow constructed wetland (SS-VF) was proposed for pre-treatment of septage before its input into the biological section of a municipal WWTP (Figure 1).

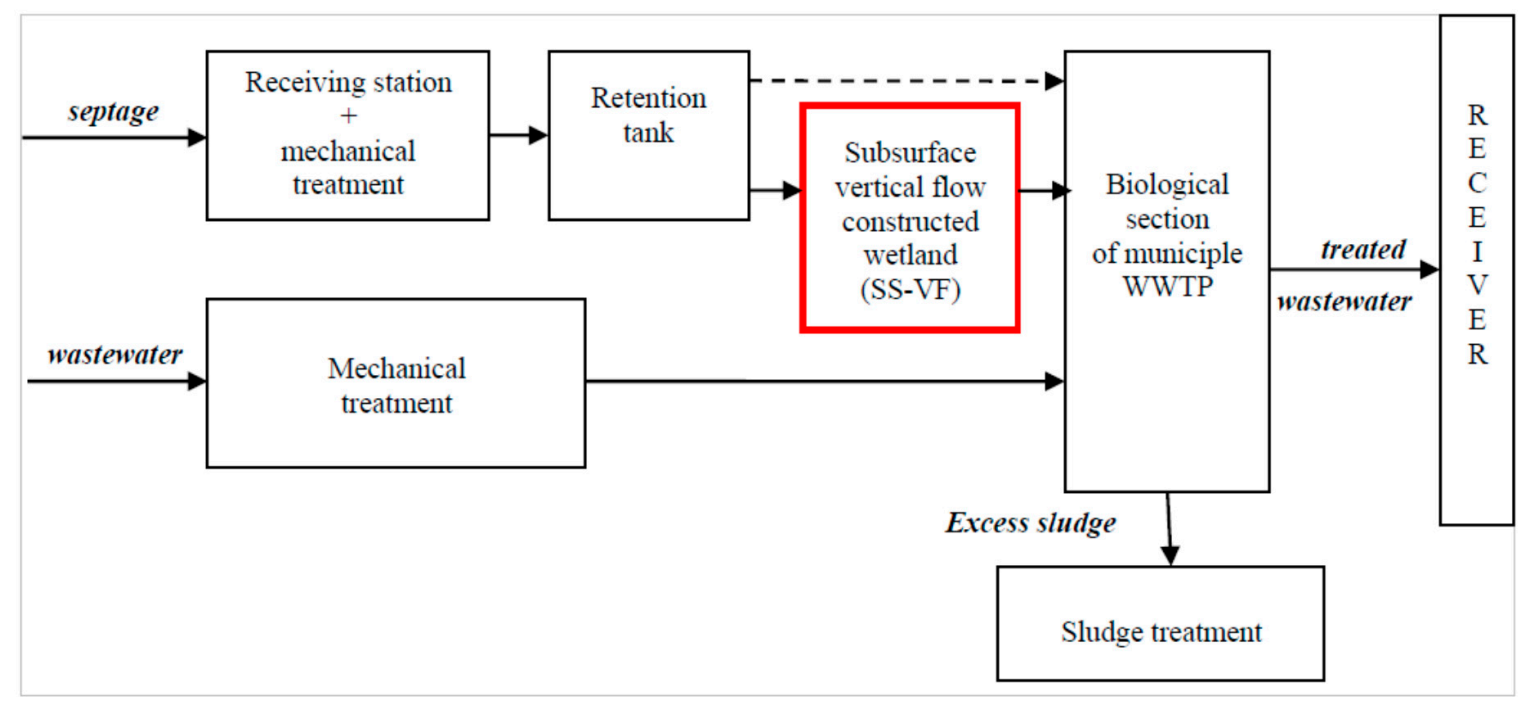

Figure 1. System for wastewater and septage treatment in a municipal wastewater treatment plant (WWTP).

Constructed wetlands (CWs) are used worldwide for treatment of municipal and industrial wastewater, reject water and landfill leachate as well as for sludge treatment [11-14]. In case of septage, the application of CWs was aimed to dewater and consolidate the sludge-type wastewater instead of removing pollutants [15-18]. The research results presented by the authors of this paper [19] show that the use of the SS-VF bed for septage pre-treatment also allows to reduce the value of pollution indicators by: biochemical oxygen demand $\left(\mathrm{BOD}_{5}\right): 82 \%$, chemical oxygen demand (COD): $82 \%$, suspended solids (SS) 91\%, total nitrogen (TN): 47\%, total Kjeldahl nitrogen (TKN): 71\%, ammonia nitrogen $\left(\mathrm{NH}_{4}-\mathrm{N}\right): 70 \%$, total phosphorus (TP): $79 \%$. The research was conducted over a 12-month period using a pilot-scale installation built in one of the municipal WWTP in north-eastern Poland. The SS-VF bed with a $5 \mathrm{~m}^{2}$ surface area and $0.65 \mathrm{~m}$ depth was planted with Phragmines australis. The bed consisted of three layers: $0.15 \mathrm{~m}$ stones, $0.35 \mathrm{~m}$ gravel and $0.15 \mathrm{~m}$ sand. The results of research carried out under other conditions and by means of different systems were described by Tan et al. [20] and Bui et al. [21].

By directing septage pre-treated in the SS-VF bed to the biological section of the WWTP its pollution load is reduced. Initially, input of the SS-VF bed into the system allows to reduce the required treatment effectiveness in the biological section of the WWTP. In addition, it is also expected to generate an economic effect in the form of reduced treatment costs. The use of an optimization model allows to analyze an infinite number of variants.

Cost optimization models differ in terms of the value of the parameter affecting costs-decision variable: the coefficient of septage stream distribution into the quantity directed to the SS-VF bed in relation to its total quantity. The cost function is not linear in terms of flow and treatment efficiency. An optimization model allows to determine its value with the lowest possible expected annual cost of both wastewater and septage. The closest cost model described in literature concerns optimization of sewage and sludge treatment [22]. This issue is also addressed in the papers [23,24], but none of them introduce a the SS-VF bed for septage pre-treatment. To the best knowledge of the authors, there are no studies focusing on the economic aspects of overloading WWTPs with the load of pollutants contained in septage. All that is known is that an excessive load of pollutants increases treatment costs [9]. The objective of this paper is to assess the cost-effectiveness of septage pretreatment in the SS-VF bed by means of an optimization model. 


\section{Mathematical Modeling}

The optimization model consists of: optimization criterion (1), decision variables (2), constraints (3), boundary conditions of decision variables (4), objective function (5), model solution algorithm (6), computer program (7), verification of the optimization model (8) and interpretation of the optimization results (9). Cost minimization is most often the optimization criterion (1) in the economic optimization models. This criterion is consistent with the principle of rational management, according to which the greatest economic effectiveness is obtained when a certain effect is achieved with the lowest cost [25]. This cost is understood as an expected annual cost, including investment outlays and operating costs. Using the cost-effectiveness analysis, it is possible to compare variants of the process giving the same use effect and to choose the one which has the minimum expected annual cost $K_{r}$ [26,27]:

$$
K_{r}=I(r+s)+K_{a}
$$

where: $K_{r}$ —expected annual cost (PLN/year), I -investment outlays (PLN), $r$ —discount rate (year ${ }^{-1}$ ), $s$-depreciation rate (year $\left.{ }^{-1}\right), K_{a}$-annual operating costs (without depreciation) (PLN/year).

The decision variable (2) is the parameter affecting the expected annual cost, whose value can be modified within the range defined by the constraints and boundary conditions. Constraints (3) are conditions resulting from the legal and technical requirements. Boundary conditions of decision variables (4) are conditions resulting from the physical essence of the decision variable. The objective function (5) is usually the expected annual cost function, determined on the basis of real data. The solution of the optimization model requires the development of an algorithm (6). According to it, at the beginning, the lowest possible value of the expected annual cost is determined and then the corresponding value of the decision variable is searched. In other words, an examination is carried out for a variant in which the expected annual cost function reaches the minimum level. A computer program (7) is then built on the basis of the algorithm of the optimization model solution. Using real sample data, verification of the developed optimization model (8) and interpretation of optimization results (9) are carried out. The following variants of the process are considered:

VARIANT ZERO: no septage pre-treatment in the SS-VF bed before its input into the biological section of a municipal WWTP (Figure 2).

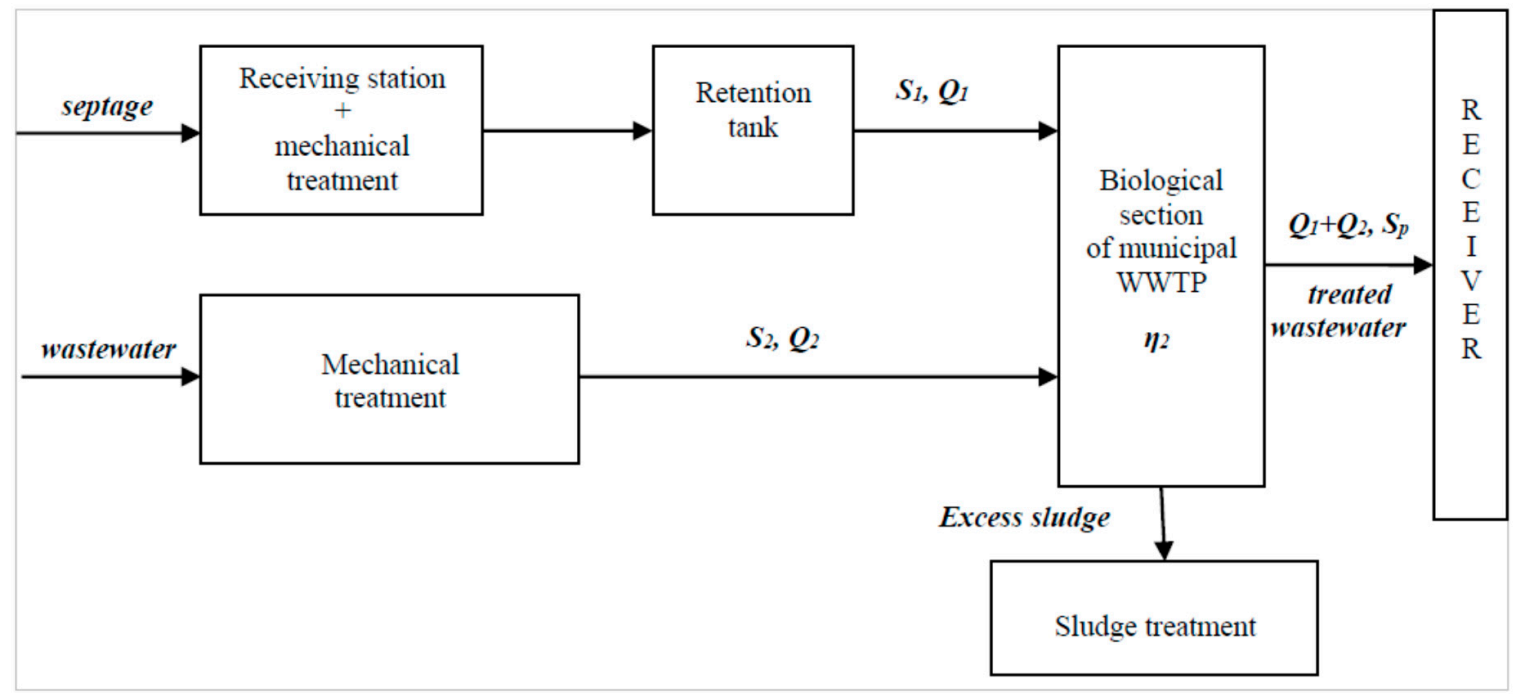

Figure 2. Block diagram of the variant zero of wastewater and septage treatment.

Septage is fed into a receiving station equipped with a mechanical treatment device and then into a retention tank from where, after averaging the concentrations to $S_{1}$, the quantity $Q_{1}$ is directed to the biological section of a municipal WWTP. 
Mechanically treated wastewater with concentration $S_{2}$ and quantity $Q_{2}$ is fed into the biological section of a WWTP. There, the mixture of septage $\left(Q_{1}, S_{1}\right)$ and wastewater $\left(Q_{2}, S_{2}\right)$ undergoes a treatment process with efficiency $\eta_{2}$, allowing to reduce the concentration of pollutants in wastewater discharged into the receiver $\left(Q_{1}+Q_{2}\right)$ to the maximum permissible level $\left(S_{p}\right)$.

ALTERNATIVE VARIANT: the use of pre-treatment of septage in the SS-VF bed before its input into the biological section of a municipal WWTP (Figure 3).

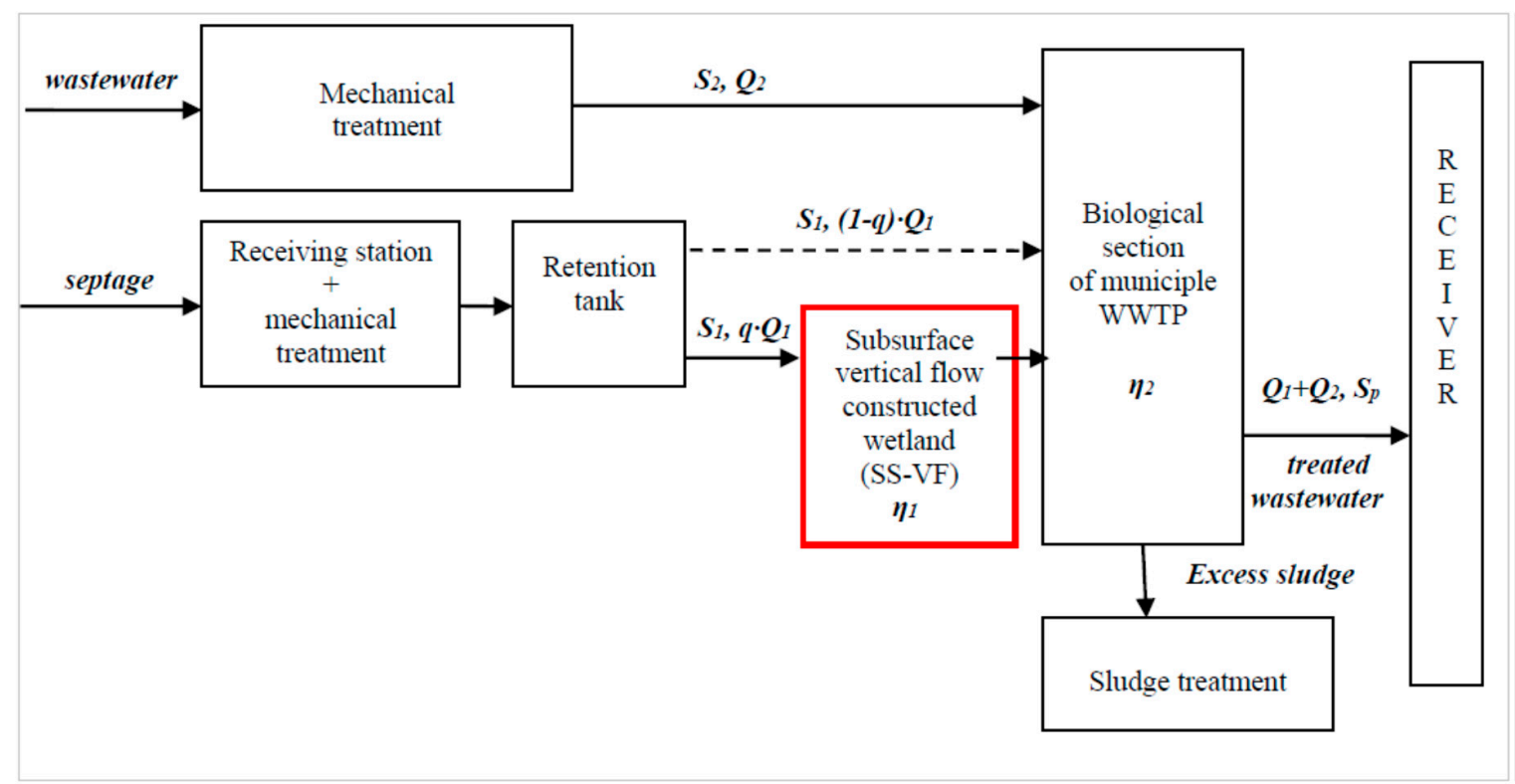

Figure 3. Block diagram of the alternative variant of wastewater and septage treatment—optimization issue.

Septage is fed into a receiving station equipped with a mechanical treatment device and then into a retention tank from where, after averaging the concentrations to $S_{1}$, the amount of $Q_{1}$ is directed to the biological treatment. The part of that total septage quantity $\left(Q_{1} \cdot q=Q_{1^{\prime}}\right)$ is input into the SS-VF bed, where it is pretreated with efficiency $\eta_{1}$. The rest of the septage $\left.\left\{(1-q) \cdot Q_{1}\right)\right\}$ is transferred directly into to the biological section of a WWTP. The optimization task is to determine the optimal coefficient of septage stream distribution $q=Q_{1^{\prime}} / Q_{1}$. For technological reasons, the same septage should be directed to the biological section of a WWTP and excluded from optimization. This is important in the case of large WWTPs, for which a high efficiency of nutrient removal requires addition of an external carbon source [28]. Organic compounds contained in septage may provide an external carbon source for the denitrification process.

Wastewater is subjected to pre-treatment in the mechanical section, from which (along with the concentration $S_{2}$ and quantity $Q_{2}$ ) it is transferred into the biological section of the WWTP. There, the mixture of septage $\left(Q_{1}, S_{1}\right)$ and wastewater $\left(Q_{2}, S_{2}\right)$ undergoes a treatment process with efficiency $\eta_{2}$, allowing to reduce the concentration of pollutants in wastewater discharged into the receiver $\left(Q_{1}+Q_{2}\right)$ to the maximum permissible level $\left(S_{p}\right)$.

\section{Results}

The result of the research was the development of an optimization model whose structure is presented below.

(1) Optimization criterion:

The optimization criterion is the minimization of the expected annual cost of wastewater and septage treatment

$$
K=K_{1}+K_{2} \rightarrow \min
$$


$K_{1}$ - expected annual cost of septage pre-treatment in SS-VF bed (PLN/year)

$K_{2}$ - expected annual cost of treatment in the biological section of a WWTP (PLN/year).

(2) Decision variables:

$q$-coefficient of septage stream distribution into the quantity directed to the SS-VF bed in relation to its total quantity (-).

(3) Objective function:

Function of the expected annual cost consisting of the sum of the function of the annual cost of septage pre-treatment in the SS-VF bed $\left(K_{1}\right)$ and the function of the annual cost of treatment in the biological section of a WWTP $\left(K_{2}\right)$ :

$$
K\left(q, \eta_{2}\right)=K_{01}\left(q Q_{1}\right)^{\alpha_{1}}\left(\frac{\eta_{1}}{1-\eta_{1}}\right)^{\gamma_{1}}+K_{02}\left(Q_{1}+Q_{2}\right)^{\alpha_{2}}\left(\frac{\eta_{2}}{1-\eta_{2}}\right)^{\gamma_{2}} \rightarrow \min
$$

q-a.m.

$Q_{1}$-septage flow $\left(\mathrm{m}^{3} /\right.$ year $)$,

$Q_{2}$-wastewater flow ( $\mathrm{m}^{3} /$ year),

$\eta_{1}$-effectiveness of septage pre-treatment in SS-VF bed (-),

$\eta_{2}$-effectiveness of treatment in the biological section of a WWTP (-),

$K_{01}, \alpha_{1}, \gamma_{1}$-power regression coefficients of the cost function of septage pre-treatment in SS-VF (-),

$K_{02}, \alpha_{2}, \gamma_{2}$-power regression coefficients of the cost function of treatment in the biological section of a WWTP (-).

The values of coefficients $K_{0}, \alpha, \gamma$ are determined on the basis of real sample data obtained from WWTPs operators. For this purpose, it is necessary to obtain data concerning the expected annual cost of treatment $\left(K_{r}\right)$ and the effectiveness $(\eta)$ of at least four WWTPs. To determine the power regression coefficients a computer program "Modeling of wastewater treatment costs" was developed (Figure 4) (programmer Malinowski P).

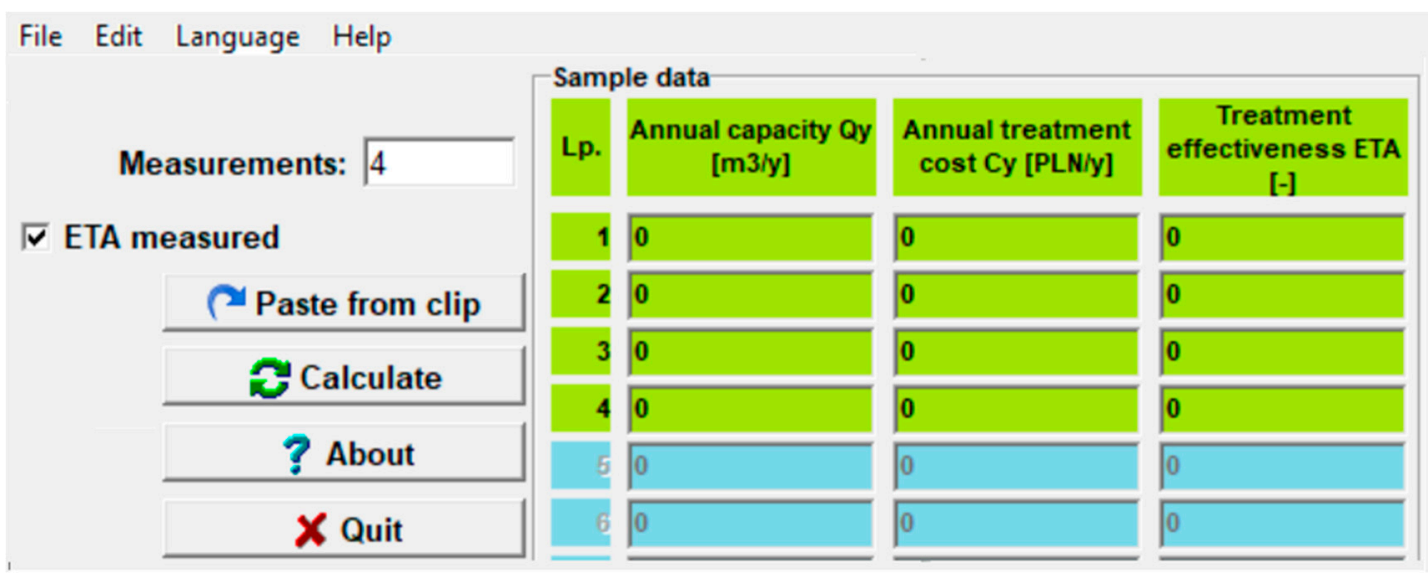

Figure 4. Computer program: "Modelling of wastewater treatment costs".

(4) Constraints:

Constraints result from legal requirements which regard the quality of treated wastewater discharged into a receiver. The sum of the loads $\left(L_{1}\right),\left(L_{2}\right)$ and $\left(L_{3}\right)$ cannot be greater than the permitted discharged load $\left(L_{p}\right)$ :

$$
\underbrace{q Q_{1} S_{1}\left(1-\eta_{1}\right)\left(1-\eta_{2}\right)}_{L_{1}}+\underbrace{(1-q) S_{1} Q_{1}\left(1-\eta_{2}\right.}_{L_{2}}) \underbrace{+S_{2} Q_{2}\left(1-\eta_{2}\right)}_{L_{3}} \leq \underbrace{\left(Q_{1}+Q_{2}\right) S_{p}}_{L_{p}}
$$


$L_{1}$ - pollution load in septage treated in the SS-VF bed and in the biological section of a WWTP $(\mathrm{kg} /$ year),

$L_{2}$ - pollution load in septage excluding SS-VF bed ( $\mathrm{kg} /$ year),

$\mathrm{L}_{3}$ - pollution load in treated wastewater ( $\mathrm{kg} /$ year),

$L_{p}$ - permissible input pollution load into a receiver ( $\mathrm{kg} /$ year).

After simplification, inequality (4) is reduced to:

$$
\eta_{2} \geq 1-\frac{\left(Q_{1}+Q_{2}\right) S_{p}}{S_{1} Q_{1}\left(1-\eta_{1} q\right)+S_{2} Q_{2}}
$$

$q, Q_{1}, Q_{2}, \eta_{1}, \eta_{2}-\mathrm{S} / \mathrm{A}$

$S_{1}$ - pollutant concentration in septage $\left(\mathrm{g} / \mathrm{m}^{3}\right)$,

$S_{2}$ - pollutant concentration in wastewater $\left(\mathrm{g} / \mathrm{m}^{3}\right)$,

$S_{p}$-maximum permissible level of the pollutants concentration in wastewater discharged into the receiver $\left(\mathrm{g} / \mathrm{m}^{3}\right)$.

(5) Constraints of decision variables: $q(0 ; 1-\kappa)$

«-part of septage which, for technological reasonsshould enter the biological section of a WWTP (excluded from optimization).

(6) Model solution algorithm:

Stage 1: Optimization concentrated on $\eta_{2}$

In the first step, the value of $\eta_{2}$ is sought in which the expected annual cost of treatment in the biological section of a WWTP will be the lowest, i.e.,

$$
\begin{gathered}
\frac{\partial K\left(q, \eta_{2}\right)}{\partial \eta_{2}}=\frac{\partial K_{2}\left(q, \eta_{2}\right)}{\partial \eta_{2}}=K_{02}\left(Q_{1}+Q_{2}\right)^{\alpha_{2}} \gamma_{2}\left(\frac{\eta_{2}}{1-\eta_{2}}\right)^{\gamma_{2}-1} \frac{1}{\left(1-\eta_{2}\right)^{2}}= \\
=c_{1}\left(\frac{\eta_{2}}{1-\eta_{2}}\right)^{\gamma_{2}-1} \frac{1}{\left(1-\eta_{2}\right)^{2}} \geq 0 \text { dla } \eta_{2} \in[0,1)
\end{gathered}
$$

The cost of treatment in the biological section of a WWTP increases with the increase in $\eta_{2}$, therefore its minimum possible value resulting from legal requirements concerning the pollutants concentration in wastewater discharged into the receiver should be included, i.e.,

$$
K\left(q, \eta_{2}\right)=\min \left(K\left(q, \eta_{2}\right)\right) \Leftrightarrow \eta_{2}=\min \left(\eta_{2}\right)=1-\frac{\left(Q_{1}+Q_{2}\right) S_{p}}{S_{1} Q_{1}\left(1-\eta_{1} q\right)+S_{2} Q_{2}}
$$

Stage 2: Optimization concentrated on the decision variable $q$

The value of $\eta_{2}$ determined in step 1 will depend on the decision variable $q$, i.e.,

$$
\eta_{2}(q)=1-\frac{\left(Q_{1}+Q_{2}\right) S_{p}}{S_{1} Q_{1}\left(1-\eta_{1} q\right)+S_{2} Q_{2}}
$$

As a result, the problem of optimizing the objective function concentrates on minimizing the function of the decision variable $q$, i.e.,

$$
K\left(q, \eta_{2}(q)\right)=K(q)=K_{01}\left(q Q_{1}\right)^{\alpha_{1}}\left(\frac{\eta_{1}}{1-\eta_{1}}\right)^{\gamma_{1}}+K_{02}\left(Q_{1}+Q_{2}\right)^{\alpha_{2}}\left(\frac{\eta_{2}(q)}{1-\eta_{2}(q)}\right)^{\gamma_{2}}
$$

(7) Computer program:

The issue of optimization is solved by "Cost optimization of wastewater and septage treatment process", a computer program prepared for this purpose (programmer Malinowski P). It calculates 
the value of $K\left(q_{i}\right)$ for each variable $q_{i}=i \varepsilon$, assuming the discretization of decision variable $q$ with the step $\varepsilon=10^{-6}$, where $i=0,1,2, \ldots,(1 / \varepsilon)$. It then selects the value of $q_{i}$ for which the cost reaches the minimum value. In the next step, the value of $\eta_{2}$ is calculated according to previous equations.

(8) Verification of the optimization model and interpretation of the optimization results:

The verification of the optimization model consists of checking the correctness of the algorithm of its solution using real data concerning flow rates, $\mathrm{BOD}_{5}$ concentrations and the cost function coefficient.

\section{Discussion-Verification of the Optimization Model}

The discussion of the research results is based on the verification of the developed optimization model. It was performed in the three examples, using real data from WWTPs. These examples differ in the form of cost function, which was built based on the data appropriate for each WWTP. The data on septage and wastewater stream and $\mathrm{BOD}_{5}$ load were provided by WWTPs operators.

\subsection{Example One}

The example concerns a small WWTP located in a rural area. The share of septage in the total flow is $3 \%$. The share of the $\mathrm{BOD}_{5}$ load contained therein is $12 \%$ of the WWTP total load. The input data are shown in Figure 5. The results of optimization are presented in Figure 6.

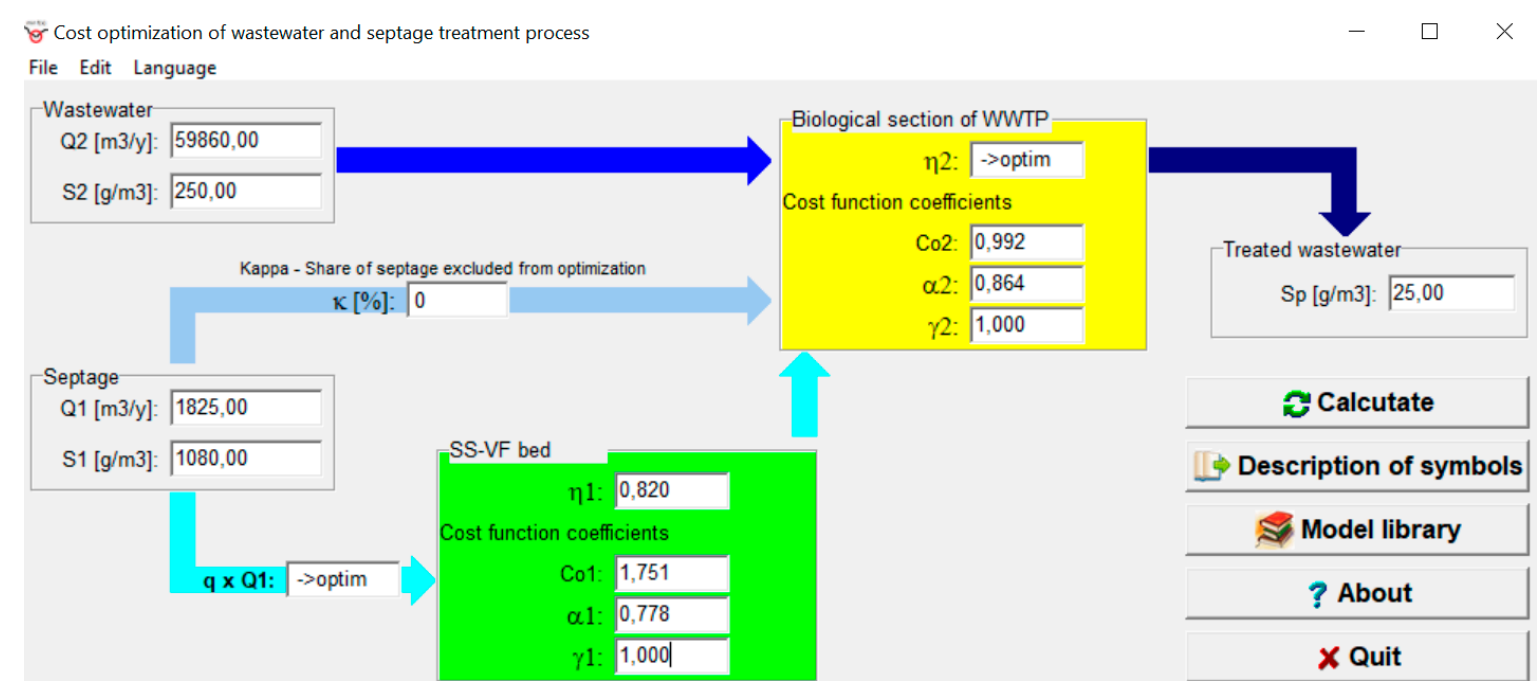

Figure 5. Computer program "Cost optimization of wastewater and septage treatment process", example 1-summary of the input data.

For the data from example one, considering the criterion of the minimum expected annual cost of the treatment, the optimal solution will be to direct the total amount of septage to the SS-VF bed $(q=1)$. This will allow to reduce the required effectiveness of treatment in the biological section of the WWTP $\left(\eta_{2}\right)$ in the $\mathrm{BOD}_{5}$ index from $90.9 \%$ to $89.9 \%$ (Figure $6 \mathrm{a}$ ). Figure $6 \mathrm{~b}$ summarizes the dependence of costs $\left(K_{1}, K_{2}, K\right)$ on the value of the decision variable $(q)$. As the value of the decision variable $(q)$ increases, the annual cost of septage pre-treatment in the SS-VF bed $\left(K_{1}\right)$ increases (Figure $6 \mathrm{c}$ ), and the cost of treatment in the biological section of WWTP $\left(K_{2}\right)$ decreases (Figure $6 \mathrm{~d}$ ) together with the total cost of treatment $(K)$ (Figure 6e). Comparison of costs in variant zero and in alternative variant is presented in Table 1. 

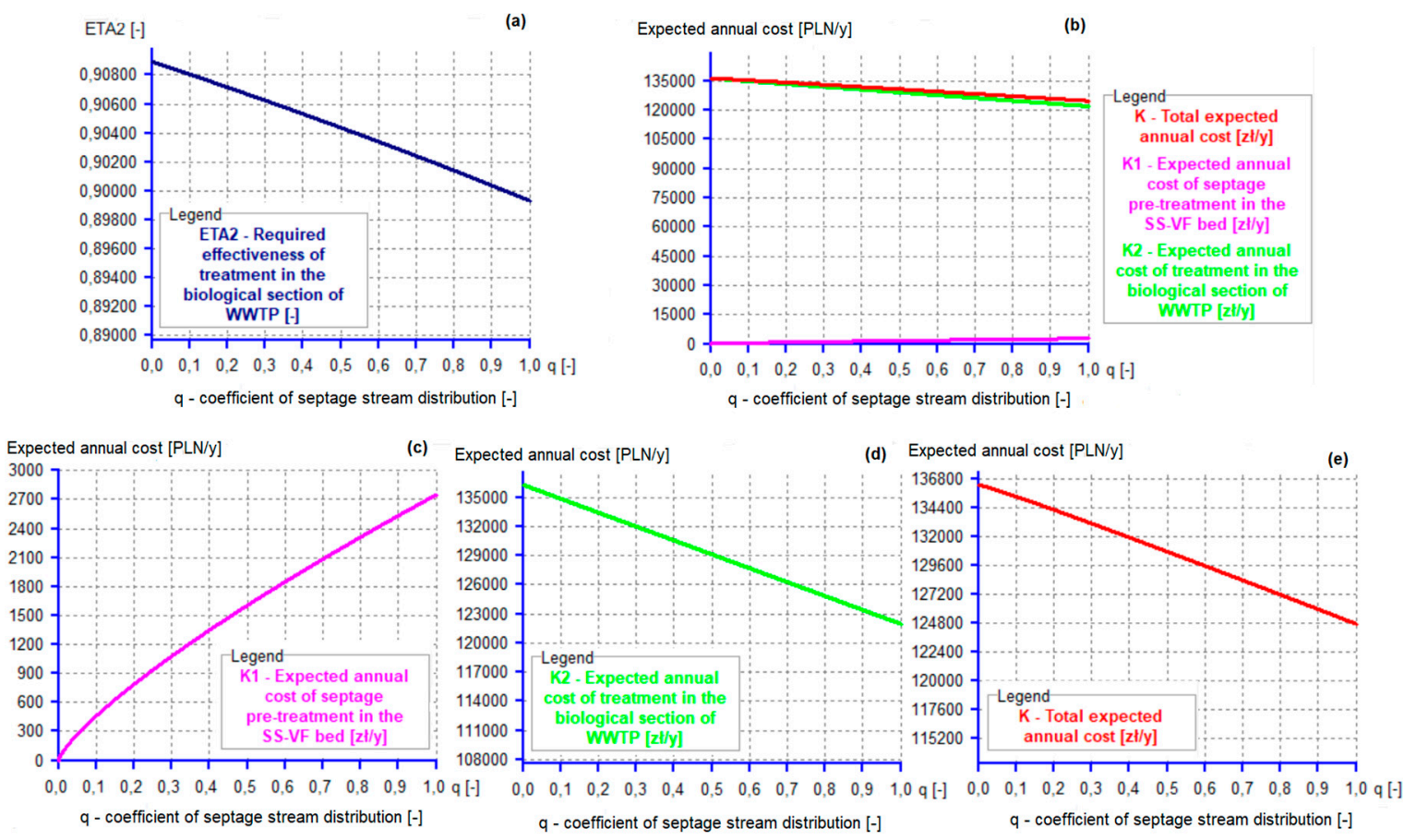

Figure 6. Example 1-summary of the dependence of decision variable on: required effectiveness of treatment in biological stage of WWTP (a) and costs $K_{1}, K_{2}, K(\mathbf{b})$, cost $K_{1}(\mathbf{c})$, cost $K_{2}(\mathbf{d})$ and cost $K(\mathbf{e})$.

Table 1. Example 1-comparison of costs in variant zero and in alternative variant.

\begin{tabular}{ccc}
\hline Expected Annual Cost (PLN/Year) & Variant Zero & Alternative Variant \\
\hline Cost of septage pre-treatment in SS-VF bed & - & 2.748 \\
Cost of treatment in the biological section of a WWTP & 136.287 & 121.978 \\
Total & 136.287 & 124.726 \\
Savings in alternative variant & & $11.561(8.5 \%)$ \\
\hline
\end{tabular}

For the analyzed data, by using the optimal solution-directing all septage to the SS-VF bed $(q=1)$ it is possible to reduce the expected annual cost of wastewater and septage treatment by $8.5 \%$.

\subsection{Example Two}

The example concerns the same small WWTP located in a rural area, however, it assumes a significant increase in septage amount. The share of septage in the total flow is $23 \%$. The share of the $\mathrm{BOD}_{5}$ load contained therein is $57 \%$ of the WWTP total load. The input data are shown in Figure 7. The results of optimization are presented in Figure 8.

For the data from example two, considering the criterion of the minimum expected annual cost of treatment, the optimal solution will be to direct the total amount of septage to the SS-VF bed $(q=1)$. This will allow to reduce the required effectiveness of treatment in the biological section of the WWTP $\left(\eta_{2}\right)$ in the $\mathrm{BOD}_{5}$ index from $94.5 \%$ to $89.5 \%$ (Figure $8 \mathrm{a}$ ). Figure $8 \mathrm{~b}$ summarizes the dependence of costs $\left(K_{1}, K_{2}, K\right)$ on the value of the decision variable $(q)$. As the value of the decision variable $(q)$ increases, the annual cost of septage pre-treatment in the SS-VF bed $\left(K_{1}\right)$ increases (Figure $8 \mathrm{c}$ ), and the cost of treatment in the biological section of WWTP $\left(K_{2}\right)$ decreases (Figure $8 \mathrm{~d}$ ) together with the total cost of treatment $(K)$ (Figure 8e). Comparison of costs in variant zero and in alternative variant is presented in Table 2. 


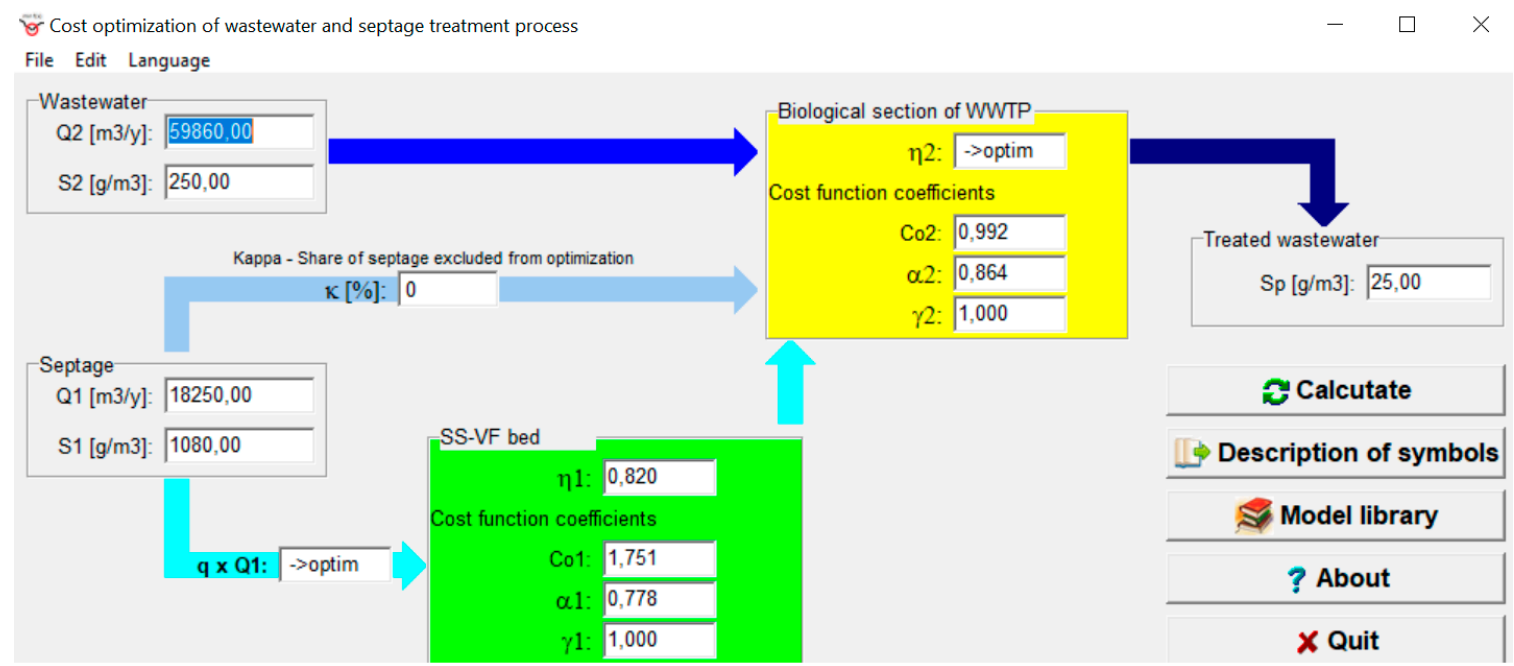

Figure 7. Computer program "Cost optimization of wastewater and septage treatment process", example 2-summary of the input data.

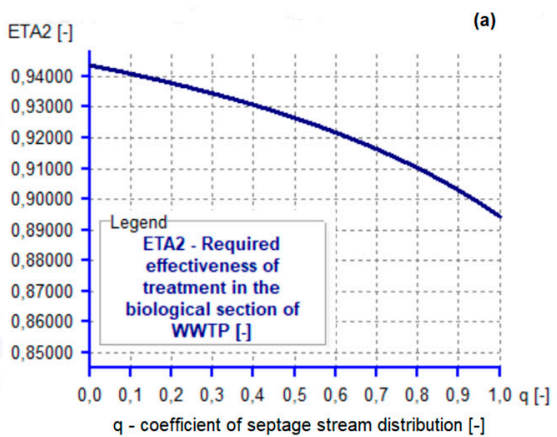

$q$ - coefficient of septage stream distribution $[-]$

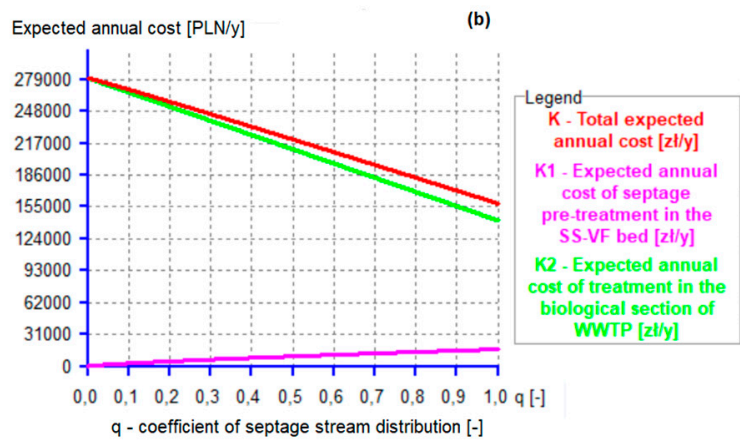

(d) Expected annual cost [PLN/y]

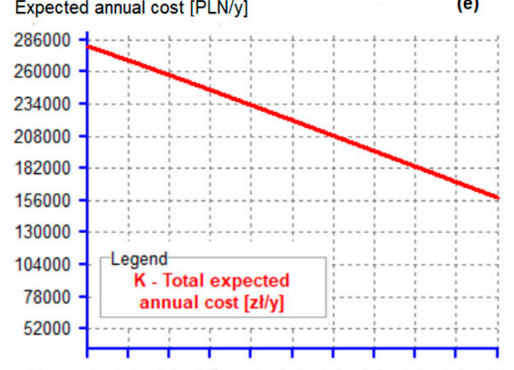

$\begin{array}{lllllllllllll}1,0 \mathrm{q}[-] & 0,0 & 0,1 & 0,2 & 0,3 & 0,4 & 0,5 & 0,6 & 0,7 & 0,8 & 0.9 & 1,0 \mathrm{q}[-]\end{array}$

$\mathrm{q}$ - coefficient of septage stream distribution [-]

Figure 8. Example 2-summary of the dependence of decision variable on: required effectiveness of treatment in biological stage of WWTP (a) and costs $K_{1}, K_{2}, K(\mathbf{b}), \operatorname{cost} K_{1}(\mathbf{c})$, cost $K_{2}(\mathbf{d})$ and cost $K(\mathbf{e})$.

Table 2. Example 2-comparison of costs in variant zero and in alternative variant.

\begin{tabular}{ccc}
\hline Expected Annual Cost (PLN/Year) & Variant Zero & Alternative Variant \\
\hline Cost of septage pre-treatment in SS-VF bed & - & 16.485 \\
Cost of treatment in the biological section of WWTP & 280.548 & 141.979 \\
Total & 280.548 & 158.464 \\
Savings in alternative variant & & $122.083(43.5 \%)$ \\
\hline
\end{tabular}

For the analyzed data, by using the optimal solution-directing all septage to the SS-VF bed $(q=1)$ it is possible to reduce the expected annual cost of wastewater and septage treatment by $43.5 \%$. 


\subsection{Example Three}

Example three is based on data from a WWTP located in an urban area, where the construction of CWs for septage treatment would require the purchase of land and additional costs of its adjustment. The share of septage in the total flow is $1 \%$. The share of the $\mathrm{BOD}_{5}$ load contained therein is $3 \%$ of the total load of the WWTP. The input data are shown in Figure 9. The results of optimization are presented in Figure 10.

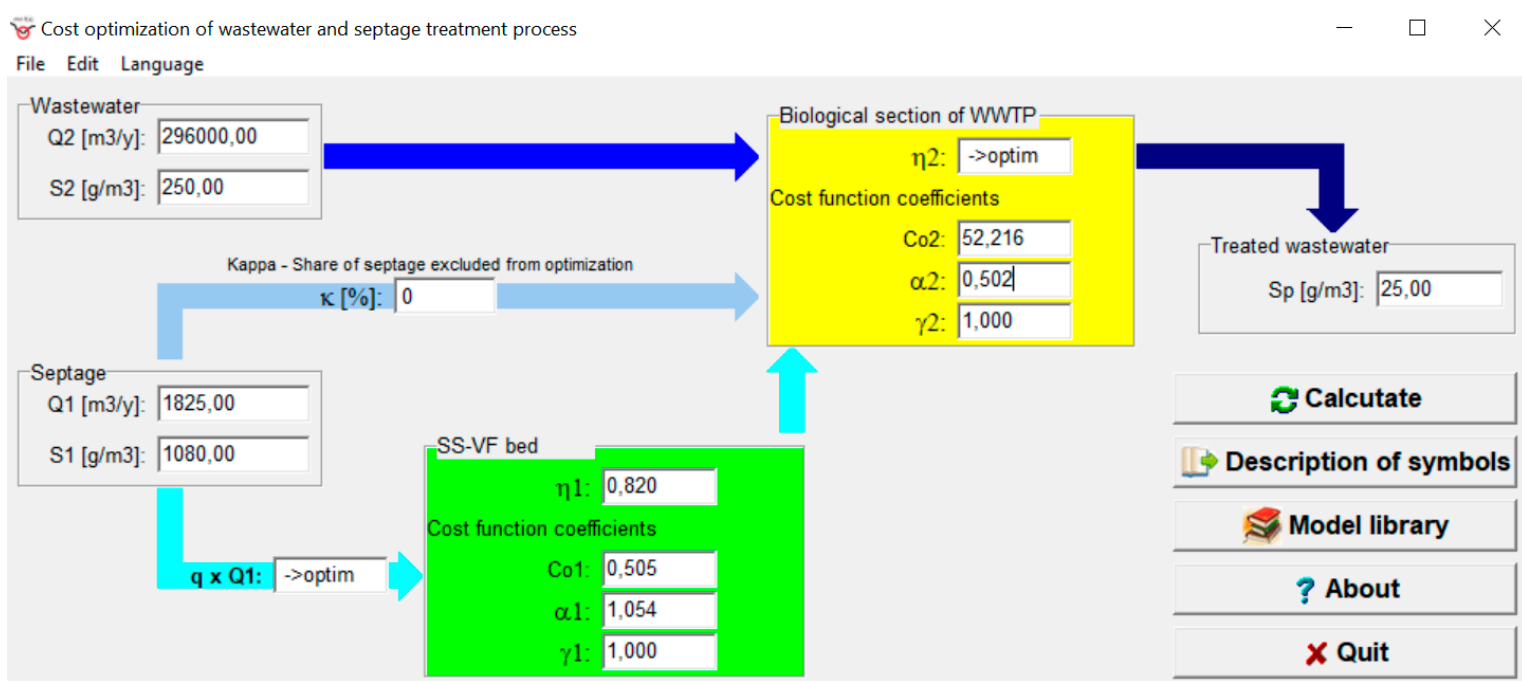

Figure 9. Computer program "Cost optimization of wastewater and septage treatment process", example 3-summary of the input data.
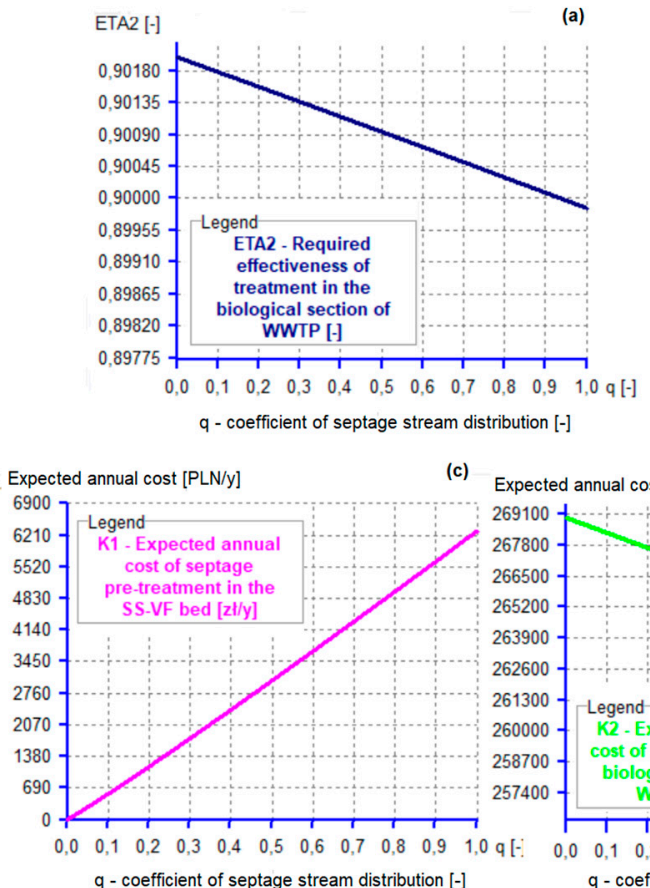

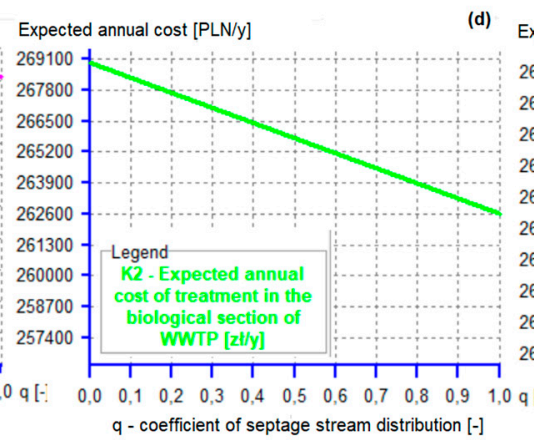

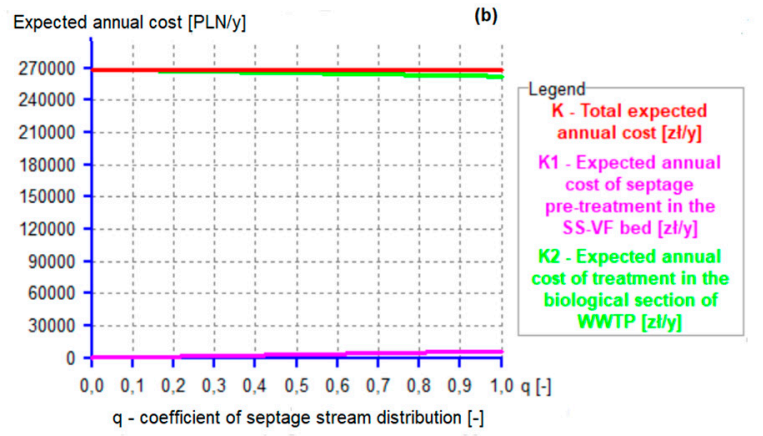

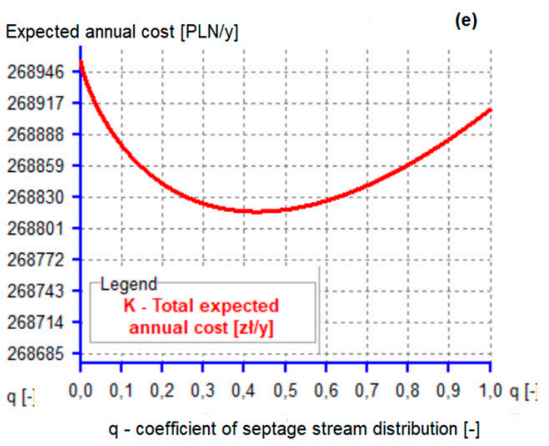

Figure 10. Example 3-summary of the dependence of decision variable on: required effectiveness of treatment in biological stage of WWTP (a) and costs $K_{1}, K_{2}, K(\mathbf{b})$, cost $K_{1}(\mathbf{c})$, cost $K_{2}$ (d) and cost $K(\mathbf{e})$.

For the data from example three, considering the criterion of the minimum expected annual cost of treatment, the optimal solution will be to direct $43 \%$ of septage amount of septage to the SS-VF bed. This will allow to reduce the required effectiveness of treatment in the biological section of the WWTP $\left(\eta_{2}\right)$ in the $\mathrm{BOD}_{5}$ index from $90.2 \%$ to $90.1 \%$ (Figure 10a). Figure $10 \mathrm{~b}$ summarizes the dependence 
of costs $\left(K_{1}, K_{2}, K\right)$ on the value of the decision variable $(q)$. As the value of the decision variable $(q)$ increases, the annual cost of septage pre-treatment in the SS-VF bed $\left(K_{1}\right)$ increases (Figure 10c), and the cost of treatment in the biological section of WWTP $\left(K_{2}\right)$ decreases (Figure 10d). The total cost of treatment $(K)$ is the lowest at $q=0.43$ (Figure 10e). Comparison of costs in variant zero and in alternative variant is presented in Table 3.

Table 3. Example 3-comparison of costs in variant zero and in alternative variant.

\begin{tabular}{ccc}
\hline Expected Annual Cost (PLN/Year) & Variant Zero & Alternative Variant \\
\hline Cost of septage pre-treatment in SS-VF bed & - & 2.597 \\
Cost of treatment in the biological section of WWTP & 268.957 & 266.220 \\
Total & 268.957 & 268.817 \\
Savings in alternative variant & & $140(0.05 \%)$ \\
\hline
\end{tabular}

For the analyzed data, by using the optimal solution-directing $43 \%$ of septage amount $(q=0.43)$ to the SS-VF bed it is possible to reduce the expected annual cost of wastewater and septage treatment by $0.05 \%$. The savings are therefore minimal.

\subsection{Comparison of Examples One to Three}

A comparison of the input data and results of the optimization model verification performed in examples one to three is presented in Table 4.

Table 4. Comparison of optimization model verification.

\begin{tabular}{lccc}
\hline & Example & Septage Share & Savings in Alternative Variant \\
\hline 1. & Small WWTP in a rural area & $3 \%$ of flow $12 \%$ of $\mathrm{BOD}_{5}$ load & $8.5 \%$ \\
2. Small WWTP in a rural area & $23 \%$ of flow $57 \%$ of $\mathrm{BOD}_{5}$ load & $43.5 \%$ \\
3. & WWTP in an urban area & $1 \%$ of flow $3 \%$ of $\mathrm{BOD}_{5}$ load & $0.05 \%$ \\
\hline
\end{tabular}

Verification of the optimization model carried out in examples one and two has shown that it is reasonable to subject all septage to pre-treatment in the SS-VF bed. For small WWTPs located in rural areas, the application of SS-VF beds for septage pre-treatment is beneficial, even in the case of small shares of septage in the WWTP load. However, the bigger the septage pollution load, the greater is the reduction in the treatment costs. As shown in example three, the proposed solution is less cost-effective in urban areas where the construction of the SS-VF bed requires land purchase and generates additional costs of its adjustment. The results of the optimization showed that it is justified to direct $43 \%$ of the total amount of septage to the SS-VF bed, however the savings achieved in this way are negligible.

\section{Conclusions}

To assess the cost-effectiveness of the septage pre-treatment process, an optimization model was used as a power objective function. The decision variable was the coefficient of septage stream distribution into the quantity directed to the SS-VF bed in relation to its total quantity. The optimization criterion was the minimization of the expected annual cost of wastewater and septage treatment. The optimization problem is solved by the program "Cost optimization of wastewater and septage treatment process".

Verification of the optimization model, carried out for small WWTPs located in rural areas, has shown that it is reasonable to subject all septage to pre-treatment in the SS-VF bed. It provides benefits even in the case of a small share of septage in the WWTP load. However, the bigger the septage pollution load of a treatment plant, the greater is the reduction in treatment costs. The application of SS-VF beds for septage pre-treatment is considerably less cost-effective in urban areas where the construction of the SS-VF bed requires land purchase and generates additional costs of its adjustment. 
Therefore the savings are negligible. Analyzing the examples, it can be seen that the optimization results largely depend on the cost function built by software "Modelling of wastewater treatment costs" using operators data. Therefore, it is important to build functions based on reliable local data.

The high cost-effectiveness of the septage pre-treatment process in the SS-VF bed results from the lower costs of its construction and operation as compared to the costs of conventional wastewater treatment facilities. By applying pre-treatment of septage in the SS-VF bed, the required degree of treatment in the biological section of a WWTP is reduced and in consequence, the cost of the process is decreased. This reduction is possible due to a decrease in electricity consumption costs in the biological section operation, as well as the costs of sewage sludge management as a consequence of their reduction.

Author Contributions: Conceptualization, B.K., R.M., W.D.; methodology, B.K., R.M., W.D.; formal analysis, B.K., investigation, B.K., W.D., resources, B.K., R.M.; writing—original draft, B.K.; R.M.; writing—review and editing, B.K., R.M., W.D.; supervision, R.M.; project administration, B.K.; funding acquisition, W.D. and B.K. All authors have read and agreed to the published version of the manuscript.

Funding: This research received no external funding.

Conflicts of Interest: The authors declare no conflict of interest.

\section{References}

1. Sheng, P.; Dong, Y.; Vochozka, M. Analysis of Cost-Effective Methods to Reduce Industrial Wastewater Emissions in China. Water 2020, 12, 1600. [CrossRef]

2. Hernandez-Sancho, F.; Molinos-Senante, M.; Sala-Garrido, R. Cost modelling for wastewater treatment processes. Desalination 2011, 268, 1-5. [CrossRef]

3. Engin, G.O.; Demir, I. Cost analysis of alternative methods for wastewater handling in small communities. J. Environ. Manag. 2006, 79, 357-363. [CrossRef] [PubMed]

4. Boller, M. Small wastewater treatment plants-A challenge to wastewater engineers. Water Sci. Technol. 1997, 35, 1-12. [CrossRef]

5. Ignatowicz, K.; Puchlik, M. Rotary biological contactor as alternative for small amount of wastewater treatment. Annu. Set Environ. Prot. 2011, 13, 1385-1404.

6. Al-Sa'ed, R.M.Y.; Hithnawi, T.M. Domestic septage characteristic and cotreatment impacts on Albireh Wastewater Treatment Plant efficiency. Diraset Eng. Sci. 2006, 33, 187-197.

7. US Environmental Protection Agency. Guide to Septage Treatment and Disposal; EPA Office of Research and Development: Washington, DC, USA, 1994.

8. Liénard, A.; Payrastre, E. Treatment of sludge from septic tanks in a reed-bed filters pilot system. In Proceedings of the 5th International Conference on Wetland Systems for Water Pollution Control, Vienna, Austria, 15-19 September 1996.

9. Paing, J.; Voisin, J. Vertical flow constructed wetlands for municipal wastewater and septage treatment in French rural area. Water Sci. Technol. 2005, 51, 145-155. [CrossRef] [PubMed]

10. Ingallinella, A.M.; Sanguinetti, G.; Koottatep, T.; Montangero, A.; Strauss, M. The challenge of faecal sludge management in urban areas-strategies, regulations and treatment options. Water Sci. Technol. 2002, 46, 285-294. [CrossRef] [PubMed]

11. Kadlec, R.H.; Wallace, S.D. Treatment Wetlands, 2nd ed.; CRC Press: Boca Raton, FL, USA, 2009.

12. Kołecka, K.; Obarska-Pempkowiak, H.; Gajewska, M. Polish experience in operation of sludge treatment reed beds. Ecol. Eng. 2018, 120, 405-410.

13. Jóźwiakowski, K.; Marzec, M.; Kowalczyk-Juśko, A.; Gizińska-Górna, M.; Pytka-Woszczyło, A.; Malik, A.; Listosz, A.; Gajewska, M. 25years of research and experiences about the application of constructed wetlands in south-eastern Poland. Ecol. Eng. 2019, 127, 440-453. [CrossRef]

14. Malinowski, P.; Dabrowski, W. Modeling of Organic Substances and Ammonia Nitrogen Removal in Vertical Flow Constructed Wetlands. J. Ecol. Eng. 2020, 21, 231-237. [CrossRef]

15. Kinsley, C.; Crolla, A. Reed Bed Filters to Treat Septage under Canadian Climatic Conditions, AOWMA Annual Conference; Ramada Convention Centre: Edmonton, Alberta, 2013. 
16. Kengne, I.M.; Dodane, P.-H.; Amougou, A.; Koné, D. Vertical-Flow Constructed Wetlands as Sustainable Approach for Feacal Sludge Dewatering in Developing Countries. Desalination 2009, 248, 291-297. [CrossRef]

17. Koottatep, T.; Surinkul, N.; Polprasert, C.; Kamal, A.S.M.; Koné, D.; Montangero, A.; Heinss, U.; Strauss, M. Treatment of septage in constructed wetlands in tropical climate: Lessons learnt from seven years of operation. Water Sci. Technol. 2005, 51, 119-126. [CrossRef] [PubMed]

18. Koné, D.; Strauss, M. Low-cost options for treating faecal sludge in developing countries-challenges and performance. In Proceedings of the 9th International IWA Specialist Group Conference on Wetlands Systems for Water Pollution Control and to the 6th International IWA Specialist Group Conference on WasteStabilisation Ponds, Avignon, France, 27 September 2004.

19. Karolinczak, B.; Dąbrowski, W. Effectiveness of septage pre-treatment in vertical flow constructed wetlands. Water Sci. Technol. 2017, 76, 2544-2553.

20. Tan, Y.Y.; Tang, F.E.; Saptoro, A.; Khor, E.H. Septage treatment using vertical-flow engineered wetland: A critical review. Chem. Eng. Trans. 2015, 45, 1531-1536.

21. Bui, J.J.X.; Tang, F.E.; Tan, Y.Y.; Wong, K.S.; Saptoto, A. Dewatering and Mineralization of Sludge in Vertical Flow Constructed Wetlands: A Review. In Proceedings of the IOP Conference Series: Materials Science and Engineering, International Conference, Sarawak, Malaysia, 26-28 November 2018.

22. Tyteca, D. Nonlinear programming model of wastewater treatment plant. J. Environ. Eng. Div. Am. Soc. Civ. Eng. 1981, 107, 747-766.

23. Gillot, S.; De Clercq, B.; Defour, D.; Simoens, F.; Gernaey, K.; Vanrolleghem, P.A. Optimization of Wastewater Treatment Plant Design and Operation Using Simulation and Cost Analysis. Available online: http:/citeseerx. ist.psu.edu/viewdoc/download?doi=10.1.1.64.1268\&rep=rep1\&type=pdf (accessed on 20 September 2020).

24. Sid, S.; Volant, A.; Lesage, G.; Heran, M. Cost minimization in a full-scale conventional wastewater treatment plant: Associated costs of biological energy consumption versus sludge production. Water Sci. Technol. 2017, 76, 2473-2481. [CrossRef]

25. Lange, O. Optimal Decisions. Principles of Programming; PWN: Warsaw, Poland, 1974; pp. 12-14. (In Polish)

26. Miłaszewski, R. Economic effectiveness of investments in water supply and sewage management and water pollution control. In Materials for Studying Water Supply and Water Pollution Control Economics, 2nd ed.; Cygler, M., Miłaszewski, R., Eds.; Economy and Environment: Białystok, Poland, 2008; pp. 56-64.

27. Karolinczak, B.; Miłaszewski, R. Application of assessment methods of the economic effectiveness of water supply and sewerage facilities. Annu. Set Environ. Prot. 2016, 18, 770-782. (In Polish)

28. Mielcarek, A.; Rodziewicz, J.; Janczukowicz, W.; Struk-Sokołowska, J. The impact of biodegradable carbon sources on nutrients removal in post-denitrification biofilm reactors. Sci. Total Environ. 2020, 720, 137377. [CrossRef] [PubMed]

Publisher's Note: MDPI stays neutral with regard to jurisdictional claims in published maps and institutional affiliations.

(C) 2020 by the authors. Licensee MDPI, Basel, Switzerland. This article is an open access article distributed under the terms and conditions of the Creative Commons Attribution (CC BY) license (http://creativecommons.org/licenses/by/4.0/). 